\title{
A Sve Light Based Technique for Power Quality Improvement for Grid Connected Wind Energy System
}

\author{
D. Shobha Rani ${ }^{1}$, Md. Mahaboob ${ }^{2}$, Md.Asif $^{3}$, P.Harika $^{4}$ \\ 1,23,4 (Department of EEE, Vardhaman College of Engineering (Autonomous), JNTU Hyderabad, India)
}

\begin{abstract}
The power produced from wind energy source is always fluctuating due to variation in the wind. Connecting this wind sources to grids leads the system to issues, and shows the impact on the functionality of the grid to be impaired. Thus wind power injection in to an electric grid affects the quality of power.. This project deals the existence of the power quality problems due to the installation of wind turbine with grid. In order to eliminate these power quality problems, this project proposes a scheme based on FACTS device called SVC light which is connected at a Point of Common Coupling. The proposed model is compared with the model that do not use any compensating device. Performance of the system with BESS under load variations and Fault ride through capability of the sve light is also analysed. This control scheme for the grid connected wind energy generation system is to improve the power quality and this system is simulated using MATLAB /SIMULINK in power system block set.
\end{abstract}

Keywords: Power Quality, Wind Generating System (WGS), Svc light, Statcom, and Fault ride through capability, Battery energy storage system (BESS).

\section{INTRODUCTION}

The wind power generation is asynchronous, and it is robust and cheap. Asynchronous generators, will not contribute to regulation of grid voltage, and they are substantial absorbers of reactive power. variations in the wind turbine, electrical power on the grid and leads to large voltage fluctuations. The power quality problems can be viewed with respect to the wind generation, transmission and distribution network, such as voltage sag, swells, flickers, harmonics etc. The wind generator introduces disturbances into the distribution network... However, induction generators require reactive power for magnetization.

Main requirements involve:

- Reactive power supply,

- Fault ride-through capability,

- Voltage control,

- Power quality control (flicker, harmonics),

- Frequency control

Some or all of which may require FACTS at the PCC to satisfy the demands. A proper control scheme in wind energy generation system is required under normal operating condition to allow the proper control over the active power production.

A svc light based control technology has been proposed for improving the power quality which can technically manages the power level associates with the commercial wind turbines. The proposed Svc light control scheme for grid connected wind energy generation for power quality improvement has following objectives.

- Unity power factor at the source side.

- Reactive power support only from svc light to wind Generator and Load

\section{Power Quality Problems}

2.1 Voltage fluctuations: The voltage fluctuation problems results from the wind speed and generator torque. The voltage variation is directly related to active and reactive power variations. The voltage variation can be:

- Voltage Sag/Voltage Dips.

- Voltage Swells.

The voltage flicker issue specifies dynamic variations in the network caused by wind turbine. Thus the power fluctuation from this turbine occurs during continuous operation. The magnitude of voltage variation depends on grid capacity, network impedance,phase-angle and power factor of the wind turbines. It is defined as a fluctuation of voltage in a frequency $10-35 \mathrm{~Hz}$. 
2.2. Harmonics: The existence of harmonics, results due to the operation of power electronic converters. The harmonic voltage and current should be limited to the prescribed level To maintain the harmonic voltage within limit, each source of harmonic current can allow only a limited contribution, as per the IEC-61400-36 guideline. The fast switching gives large reduction in lower order harmonic current compared to the line commutated converter, but the output current will have high frequency current that can be easily filter-out

2.3. Location of turbine in Power System: The way of connecting the wind turbine into the power system highly influences the quality of power. Thus the operation and its influence on power system depend on the structure of the adjoining power network.

2.4.Fault ride-through capability: Regarding fault ride-through, the grid code stipulates that the wind turbine generator (WTG) must stay connected for a close-up 3-phase fault in the transmission system that is cleared within normal protection operating times $(150 \mathrm{~ms})$. Mechanical power output during and after the fault has been cleared must not be significantly reduced. The WTG must remain stable throughout, which calls for fast remagnetization of the WTG when the grid voltage returns after the fault.

2.5. Absorption of Reactive power: Asynchronous generators require reactive power for magnetization. Induction generators, does not contribute to regulation of grid voltage, and they are absorbers of reactive power When the active power generated from induction generator is varied due to wind, absorbed reactive power and terminal voltage of an induction generator can be significantly affected.

\section{Consequences Of The Problems}

The voltage variation, harmonics badly affects equipment's namely microprocessor based control system, programmable logic controller; adjustable speed drives, flickering of light and screen. It may leads to tripping of contractors, tripping of protection devices, stoppage of sensitive equipment's like personal computer, programmable logic control system and may stop the process and even can damage of sensitive equipment ${ }^{\star}$. Thus it degrades the power quality in the grid.

\section{Power Quality Improvement}

SVC LIGHT based current control voltage source inverter injects the current into the grid in such a way that the source current are harmonic free and their phase-angle with respect to source voltage has a desired value. The injected current will cancel out the reactive part and harmonic part of the load and induction generator current, thus it improves the power factor and the power quality. To accomplish these goals, the grid voltages are sensed and are synchronized in generating the current command for the inverter. The proposed grid connected system is implemented for power quality improvement at point of common coupling (PCC), as shown in Fig. 2. The grid connected system in Fig. 2, The consists of wind energy generation system.[ref 5]

\subsection{Wind generation system}

The available power of wind energy System is presented as follows.

. pwind $=(1 / 2) \rho \mathrm{A} \mathrm{v}^{3}$ wind

Where $\rho(\mathrm{kg} / \mathrm{m})$ is the air density

A (m) is the area swept out by turbine blade,

Vwind is the wind speed in $\mathrm{mtr} / \mathrm{s}$

\subsection{SVC LIGHT}

SVC Light ${ }^{\circledR}$ is a STATCOM type of device, based on VSC (Voltage Source Converter) technology and equipped with IGBTs (Insulated Gate Bipolar Transistor) as semiconductors

\subsection{Voltage source converter}

The function of a VSC is a fully controllable voltage source matching the system voltage in phase and frequency, and with amplitude which can be continuously and rapidly controlled, so as to be used as the tool for reactive power control (Fig4.]. In the system, the VSC is connected to the system bus via a small reactor. With the VSC voltage and the bus voltage denoted U2 and U1 respectively, it can be shown that the output of the VSC can be expressed as follows

$$
\begin{aligned}
& \mathrm{P}=\frac{\mathrm{U}_{1} \mathrm{U}_{2} \sin \alpha}{\mathrm{x}} \\
& \mathrm{Q}=\frac{\mathrm{U}_{1} \mathrm{U}_{2}}{\mathrm{x}} \cos \alpha-\frac{\mathrm{U}_{1}{ }^{2}}{\mathrm{x}}
\end{aligned}
$$


Where:

P: Active power of the VSC

Q: Reactive power of the VSC

U1: Bus voltage

$\mathrm{U} 2$ : VSC voltage

$\alpha$ : Phase difference between the voltages

$\mathrm{X}$ : Reactance of the coupling reactor.

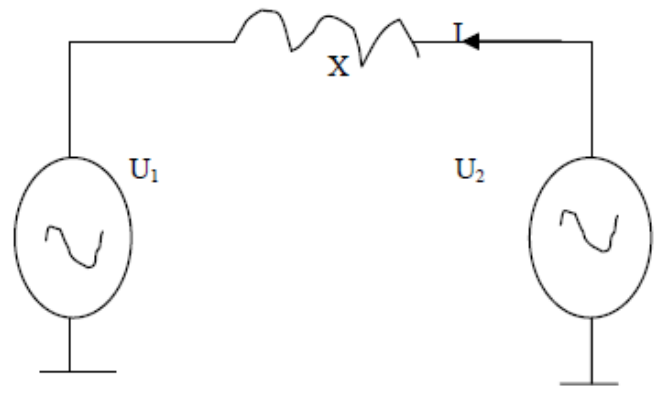

Fig 3 .VSC: a controllable voltage source

From (4) and (5) it can be seen that by choosing zero phase shift between the bus voltage and the VSC voltage $(\alpha=0)$, the VSC will act as a purely reactive element. (In reality, a small phase shift is allowed, in order to make up for the VSC losses.) It is further seen that if U2 > U1, the VSC will act as a generator of reactive power, i.e. it will have a capacitive character. If U2 < U1, the VSC will act as an absorber of reactive power, i.e.it will have an inductive character.

4.4 Converter valve: A VSC of three-level configuration is built up as in fig. One side of the VSC is connected to a capacitor bank, which acts as a DC voltage source. The converter produces a variable AC voltage at its output by connecting the positive pole, the neutral, or the negative pole of the capacitor bank directly to any of the converter outputs By use of Pulse Width Modulation (PWM), an AC voltage of nearly sinusoidal shape can be produced without any considerable need for harmonic filtering.

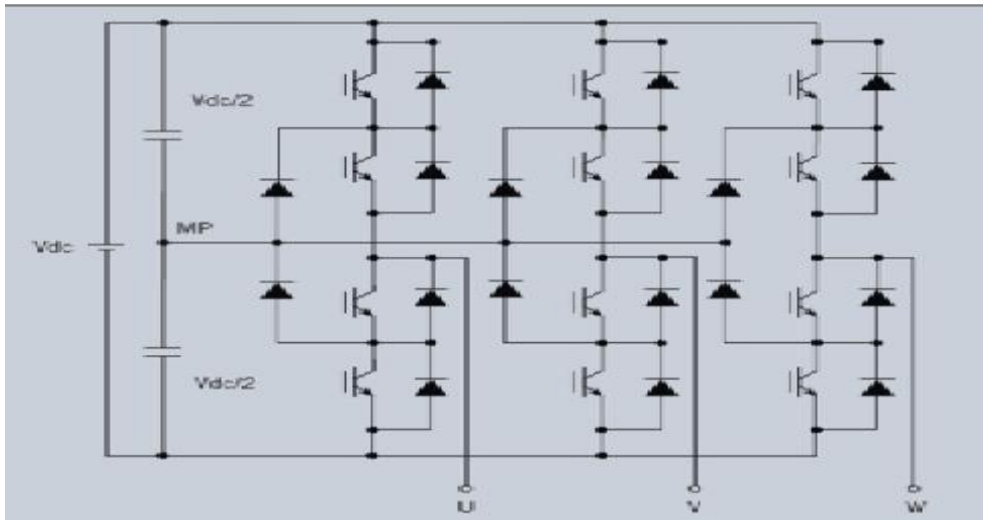

Fig. 4 3-level VSC configuration

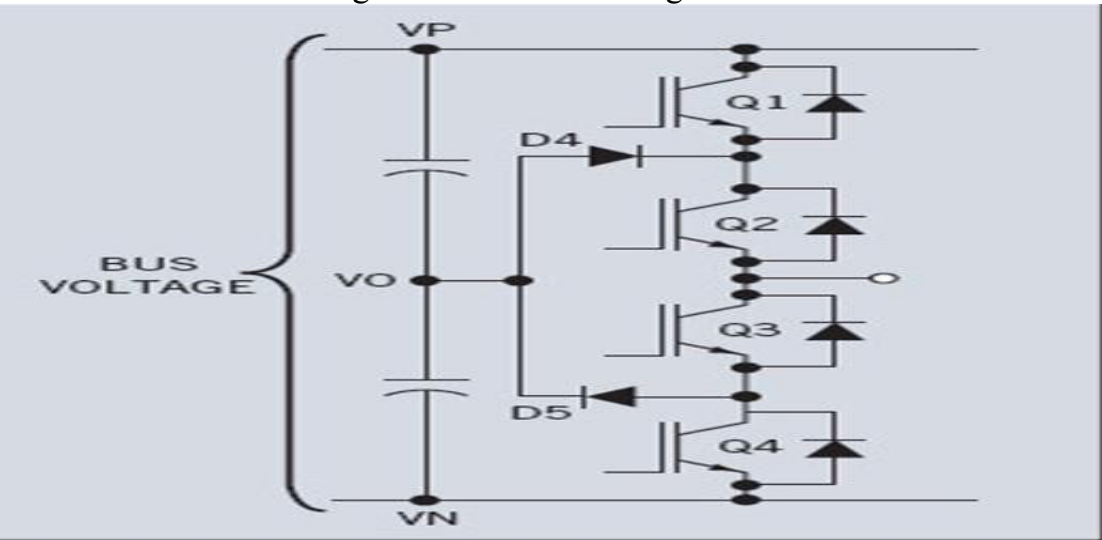

Fig. 5 single leg of VSC [ref 3] 


\begin{tabular}{c|c|c|c}
\multicolumn{5}{l}{ IGBT Vout $=$ Vp Vout $=$ Vo Vout $=$ Vn } \\
\hline Q1 & On & Off & Off \\
\hline Q2 & On & On & Off \\
\hline Q3 & Off & On & On \\
\hline Q4 & Off & Off & On
\end{tabular}

\section{Operation Of The System}

The shunt connected STATCOM with battery energy storage is connected with the interface of the induction generator and non-linear load at the PCC in the grid system. The STATCOM compensator output is varied according to the controlled strategy, so as to maintain the power quality norms in the grid system.

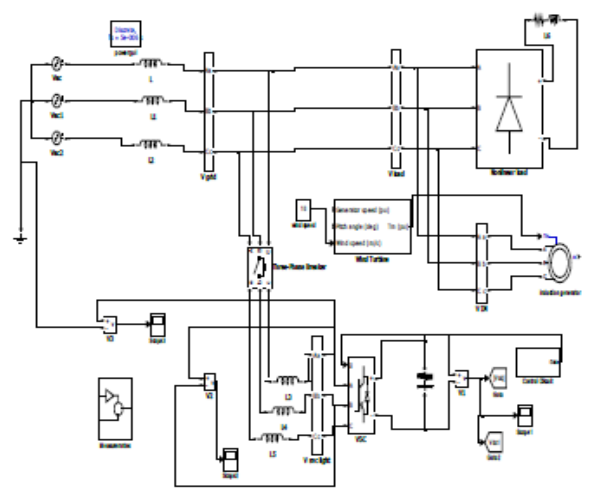

Fig 6. simulink diagram of proposed scheme

\section{Control Scheme}

The control algorithm needs the measurements of several variables such as three-phase source current isabc, DC voltage vdc, inverter current iiabc with the help of sensor. The current control block, receives an input of reference current $i *$ Sabc and actual current iSabc are subtracted so as to activate the operation of STATCOM in current control mode.

6.1 Generation of reference current: In three-phase balance system, the RMS voltage source amplitude is calculated at the sampling frequency from the source phase voltage (Vsa,Vsb,vsc ) and is expressed, as sample template $V s m$, sampled peak voltage, as in (9).

$$
\mathrm{Vs}_{\max }=\left\{(2 / 3)\left(\mathrm{V}_{\mathrm{sa}}^{2}+\mathrm{V}^{2}{ }_{\mathrm{sb}}+\mathrm{V}^{2}{ }_{\mathrm{sc}}\right)\right\}^{1 / 2}
$$

The in-phase unit vectors are obtained from AC source-phase voltage and the RMS value of unit vector as shown in (10).

$$
\begin{aligned}
\mathrm{u}_{\mathrm{sa}} & =\mathrm{V}_{\mathrm{sa}} / \mathrm{Vs}_{\max }, \mathrm{u}_{\mathrm{sb}}=\mathrm{V}_{\mathrm{sb}} / \mathrm{Vs}_{\max }, \\
\mathrm{u}_{\mathrm{sc}} & =\mathrm{V}_{\mathrm{sc}} / \mathrm{Vs}_{\max }
\end{aligned}
$$

The in-phase generated reference currents are derived using in-phase unit voltage template as, in (11)

$$
\mathrm{i}_{\mathrm{sa}}=\mathrm{I} \cdot \mathrm{u}_{\mathrm{sa}}, \mathrm{i}^{k_{\mathrm{sb}}}=\mathrm{I} \cdot \mathrm{u}_{\mathrm{sb}}, \mathrm{i}^{*} \mathrm{sc}=\mathrm{I} \cdot \mathrm{u}_{\mathrm{sc}}
$$

where I is proportional to magnitude of filtered source voltage for respective phases. This ensures that the source current is controlled to be sinusoidal. The unit vectors implement the important function in the grid connection for the synchronization for SVC LIGHT.

\subsection{Current Controller}

Bang-Bang current controller is implemented in the current control scheme. The reference current is generated as in (10) and actual current are detected by current sensors and are subtracted for obtaining a current error for a hysteresis based bang-bang controller. Thus the ON/OFF switching signals for IGBT of STATCOM are derived from hysteresis controller [19].The switching function for phase _ $\mathrm{a}^{\mathrm{c}}$ is expressed as (12). 


$$
\begin{aligned}
& \text { Is } a<\left(\text { isa }^{*}-\mathrm{HB}\right)->\mathrm{S}_{\mathrm{A}}=0 \\
& \text { Is }>\left(\text { isa }^{*}-\mathrm{HB}\right)->\mathrm{S}_{\mathrm{A}}=1
\end{aligned}
$$

where $\mathrm{HB}$ is a hysteresis current-band

\section{Performance Of The System}

Performance of the system is measured by switching the SVC LIGHT at time $t=1.2 \mathrm{sec}$.then the three phase injected current into the grid from STATCOM will cancel out the distortion caused by the nonlinear load and wind generator. The IGBT based three-phase inverter is connected to grid through the transformer. The generation of switching signals from reference current is simulated within hysteresis band of 0.08 .

7.1 Unity power factor: The source current with and without STATCOM operation is shown in Fig. 9. This shows that the unity power factor is maintained for the source power when the STATCOM is in operation.

7.2 Reactive power support: Reactive power is generated by the SVC LIGHT and reduces the burden at the Grid side. Generation of reactive power before and after the svc light is oN.

\subsection{Reduction of Harmonic distortion:}

The fig 10. Shows how THD is improved and is with in the considerable limits.

\subsection{Fault ride through capability of SVC LIGHT}

Svc light fastly injects reactive power upon Fault clearing and hence grid voltage returns to its normal value upon fault clearing. Here fault occurs at time $\mathrm{t}=0.08 \mathrm{sec}$. this fault is cleared by SVC LIGHT when it comes to on condition.

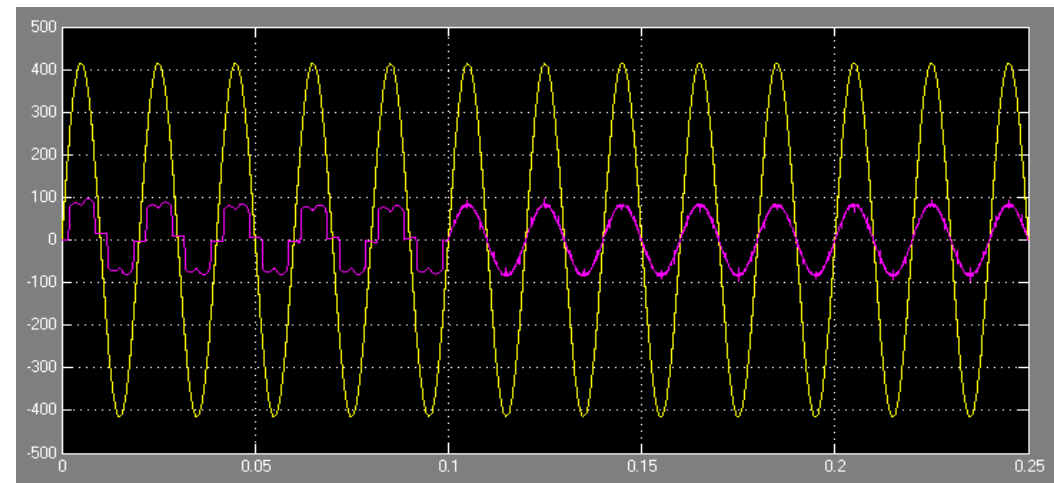

Fig 9 supply voltage and current at PCC

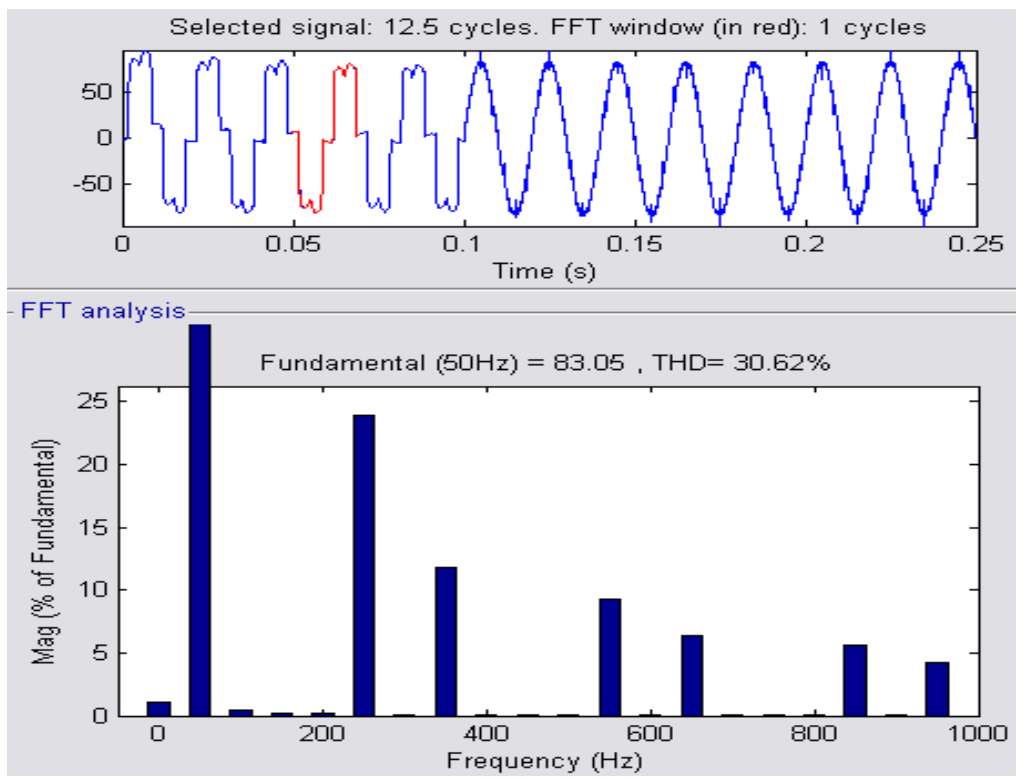

Fig 10.FFT of source current without SVC LIGHT 

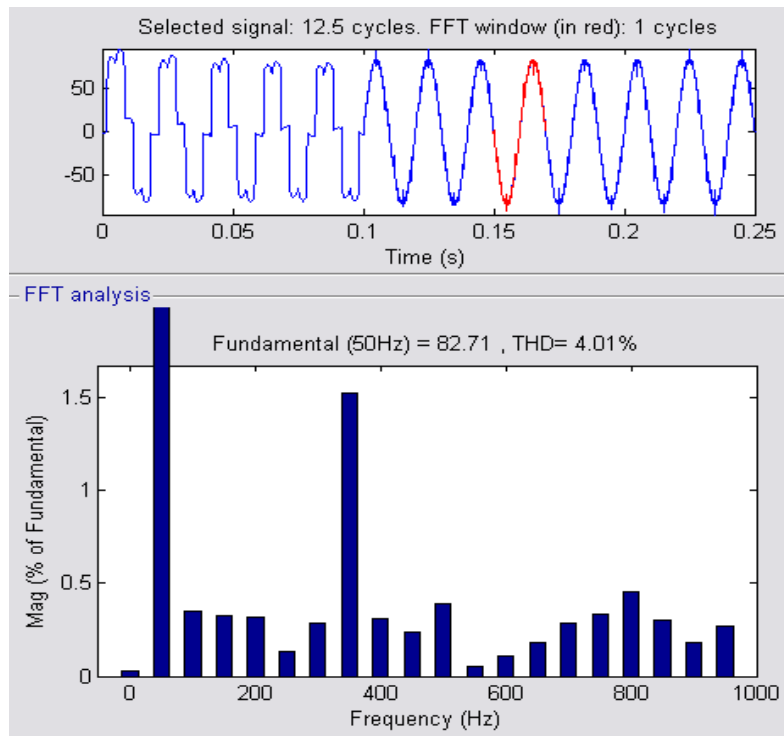

Fig 11.FFT of source current with SVC LIGHT

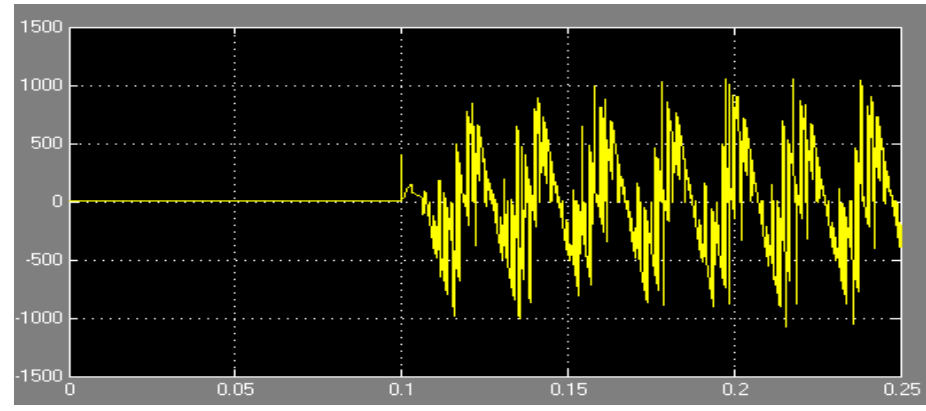

Fig 12.Current through capacitor

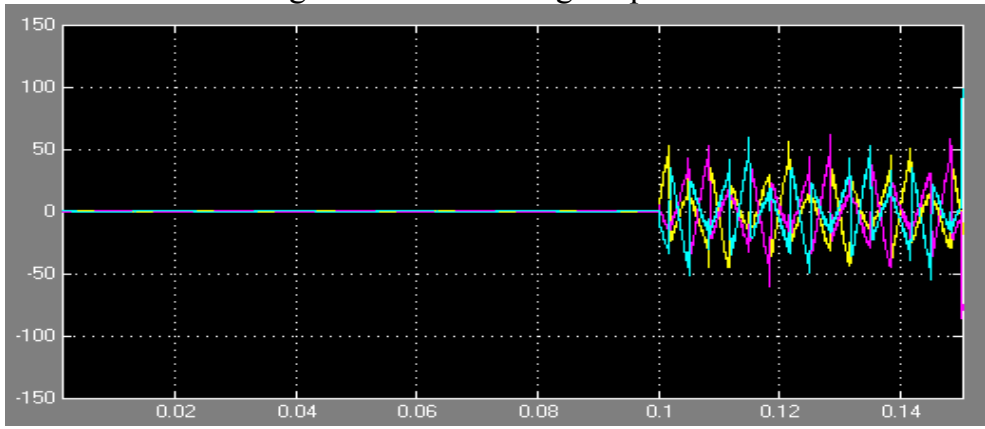

Fig.13 Three phase injected inverter current

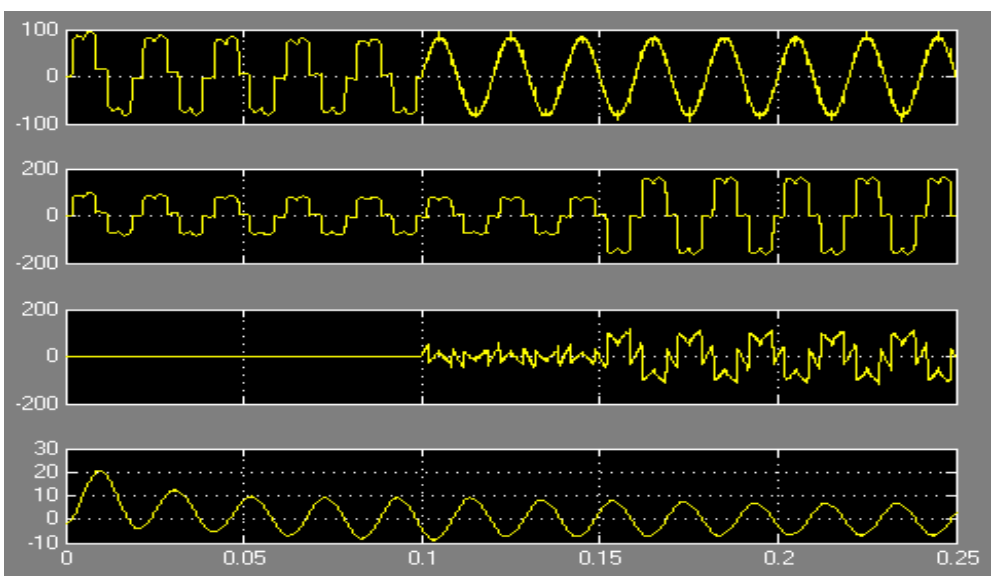

Fig 14.(a) source current. (b) Load current. (c) Inverter current. (d) Induction generator current. 


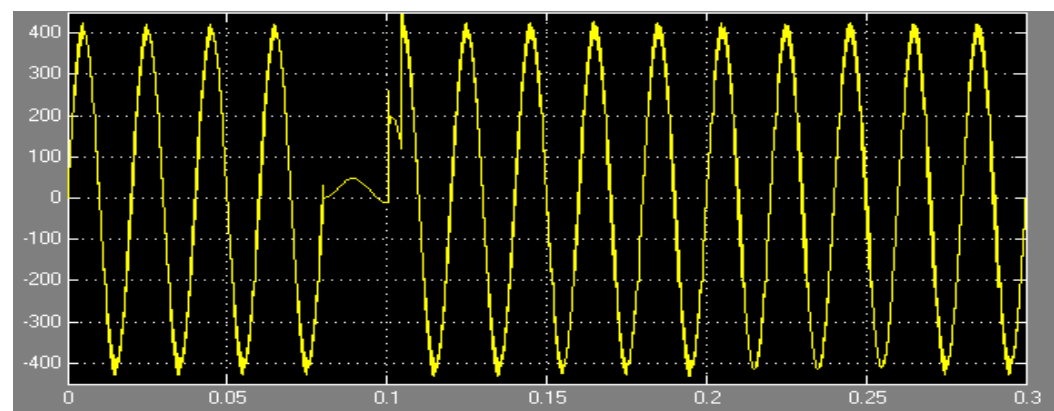

Fig 15 shows how the voltage at PCC is returned to its normal value when sve light is $\mathrm{ON}$ at time $\mathrm{t}=1.4 \mathrm{sec}$

\section{Conclusion}

In this paper, SVC LIGHT based control scheme for improvement of power quality in grid connected wind generating system and with nonlinear load is discussed. The power quality problems and its results on the consumer and electric utility are presented. The operation of the control system is developed for the SVC LIGHT in MATLAB/SIMULINK for maintaining the power quality. It has a capability to cancel out the harmonics of the load current. It maintains the source voltage and current in-phase and support the reactive power demand for the wind generator and load at PCC in the grid system and it has fault ride through capability, thus it gives an opportunity to enhance the utilization factor of transmission line. Thus the scheme here in the grid connected system fulfills the power quality.

\section{References}

[1]. A STATCOM-Control Scheme for Grid Connected Wind Energy System for Power Quality Improvement $\|$ Sharad W. Mohod, Member, IEEE, and Mohan V.

[2]. FACTS for Grid Integration of Wind Power\|Rolf Grünbaum, Member, IEEE

[3]. A Study of Wind Farm Stabilization Using DFIG or STATCOM Considering Grid RequirementsK. E Okedu* Department of Electrical/Electronic Engineering, University of Port Harcourt, Nigeria.

[4]. Yuvraj v "Improving grid power quality with FACTS device on integration of wind energy system"IEEE Trans.on E 2011

[5]. Rolf Grunbaum“FACTS for Grid integration of Wind power"IEEE power tech 2005

[6]. Belkacem mahdad "contribution to the improvement of power quality using Multi Hybrid model based wind shunt FACTS" 2011 IEEE Trans.

[7]. K. S. Hook, Y. Liu, and S.Atcitty - Mitigation of the wind generation integration related power quality issues by energy stora ge, EPQU J., vol. XII, no. 2, 2006.

[8]. Analysis of Harmonic Distortion in Non-linear Loads\| Anne Ko Department of Electrical Power Engineering Mandalay Technological University, Mandalay, Myanmar 